\title{
Spontaneous pneumomediastinum and subcutaneous emphysema in the course of COVID-19 disease: A case report and review of the literature
}

\author{
Maria Kipourou ${ }^{1,2}$, Konstantinos Karozis ${ }^{1,3}$, Savvas Lampridis ${ }^{4}$, Stergios Gkintikas ${ }^{1}$, Dimitrios Molyvas ${ }^{1}$, Prodromos
} Koutoukoglou ${ }^{1}$, Elisavet Kaitalidou ${ }^{1}$, Irina Giannopoulou ${ }^{1}$, Ioannis Tsanaktsidis ${ }^{5}$, Dimitrios Karapiperis ${ }^{1,3}$

\section{ABSTRACT}

The coronavirus disease 2019 (COVID-19), caused by the SARS-CoV-2, has resulted in widespread global morbidity and mortality. Herein, we report a case of spontaneous pneumomediastinum and subcutaneous emphysema of the neck and chest wall in a patient hospitalized with respiratory failure due to COVID-19. Since our patient was not treated with mechanical ventilation, this case demonstrates that spontaneous pneumomediastinum can appear in patients with COVID-19 regardless of barotrauma and highlights the pathophysiology of this complication.

\author{
AFFILIATION \\ 1 1st COVID Department, 424 General \\ Military Hospital (424 GMHT), Thessaloniki, \\ Greece \\ 2 Pulmonology Department, 424 General \\ Military Hospital (424 GMHT), Thessaloniki, \\ Greece \\ 3 Infectious Diseases Department, 424 \\ General Military Hospital (424 GMHT), \\ Thessaloniki, Greece \\ 4 Thoracic Surgery Department, 424 General \\ Military Hospital (424 GMHT), Thessaloniki, \\ Greece \\ 5 Radiology Department, 424 General Military \\ Hospital (424 GMHT), Thessaloniki, Greece \\ + All authors contributed equally \\ CORRESPONDENCE TO \\ Maria Kipourou. 1st COVID Department, 424 \\ General Military Hospital (424 GMHT), N. \\ Efkarpia-Thessaloniki Ring Road, Thessaloniki, \\ 56429, Greece. E-mail: mariakipo@hotmail.com
}

\section{KEYWORDS}

COVID-19, pneumomediastinum, subcutaneous emphysema

Received: 9 January 2021 Revised: 28 January 2021 Accepted: 17 March 2021

\section{INTRODUCTION}

COVID-19 is the disease caused by the novel severe acute respiratory syndrome coronavirus 2 (SARS-CoV-2), which was first detected in Wuhan, China in December 2019. COVID-19 has dominated clinical practice during two pandemic waves in our country as well as globally. New aspects of the clinical presentation of COVID-19 infection continue to emerge as more patients are infected and require hospitalization. Here, we present the case of a patient with COVID-19 infection who developed spontaneous pneumomediastinum and subcutaneous emphysema.

\section{CASE PRESENTATION}

A 62-year-old non-smoker male patient, with no medical history, was admitted to the 1st COVID department of our hospital on day 9 of COVID-19 infection, due to progressive shortness of breath. The disease had been confirmed by SARS-CoV-2 reverse transcription-polymerase chain reaction assay (RT-PCR) 7 days prior to his admission and he had received azithromycin for 5 days and methylprednisolone per os for the past 2 days. On admission, he presented with bilateral, widespread fine crackles on auscultation and respiratory failure (pO2/FiO2 ratio: 285), WBC of $12.000 \mathrm{~K} /$ $\mu \mathrm{L}$, CRP of $6 \mathrm{mg} / \mathrm{dL}$ (normal values $<0.5 \mathrm{mg} / \mathrm{dL}$ ), D-Dimers $0.6 \mu \mathrm{g} / \mathrm{mL}$ (normal values $<0.5 \mu \mathrm{g} / \mathrm{mL}$ ) and ferritin of 500 $\mathrm{ng} / \mathrm{mL}$. His chest $X$-ray is shown in Figure 1.

Treatment with remdesivir (100 mg od after an initial dose of $200 \mathrm{mg}$ iv) and recombinant human interleukin-1 receptor antagonist (100 $\mathrm{mg}$ od) was initiated, while methylprednisolone was continued (60 mg od iv). Oxygen therapy was gradually escalated during the first days of hospitalization and by day 12 of illness the patient was on High Flow Nasal Cannula (HFNC) 60 lpm and FiO2 95\% 
Figure 1. Chest X-Ray on admission (Day 9 of illness), with bilateral linear airspace opacities

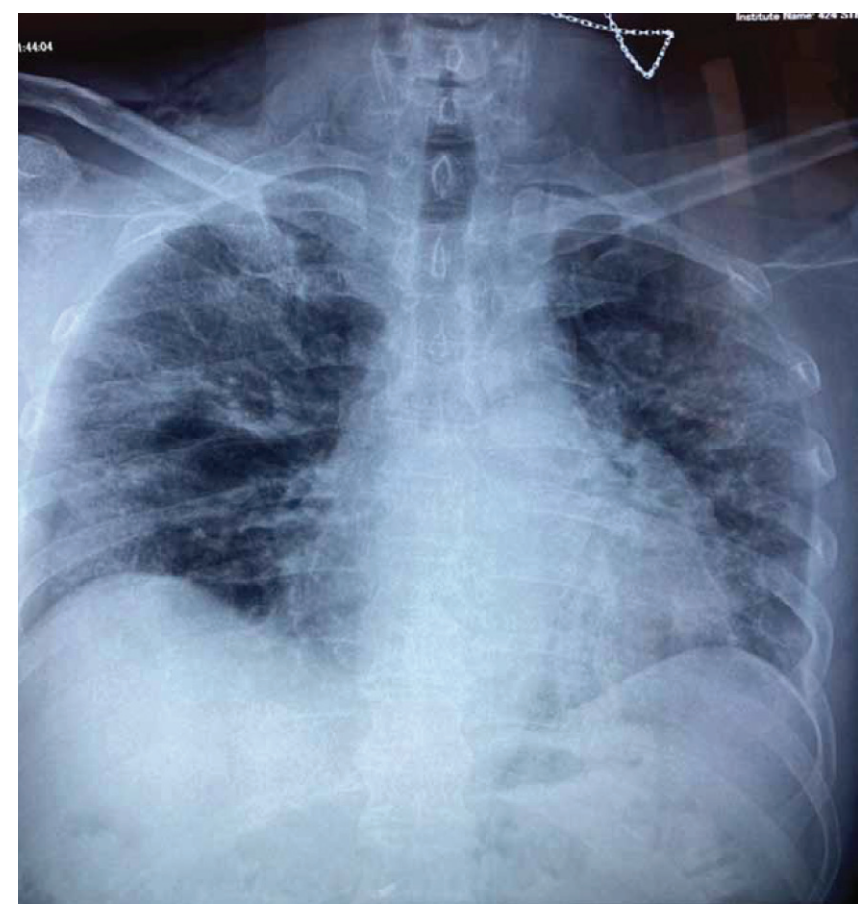

Figure 2. Routine Chest X-Ray on Day 15 of illness. Presence of air around the aorta (Ring Sign- black arrow), pneumo-mediastinum, subcutaneous emphysema of the neck and chest wall along with diffuse bilateral airspace opacities

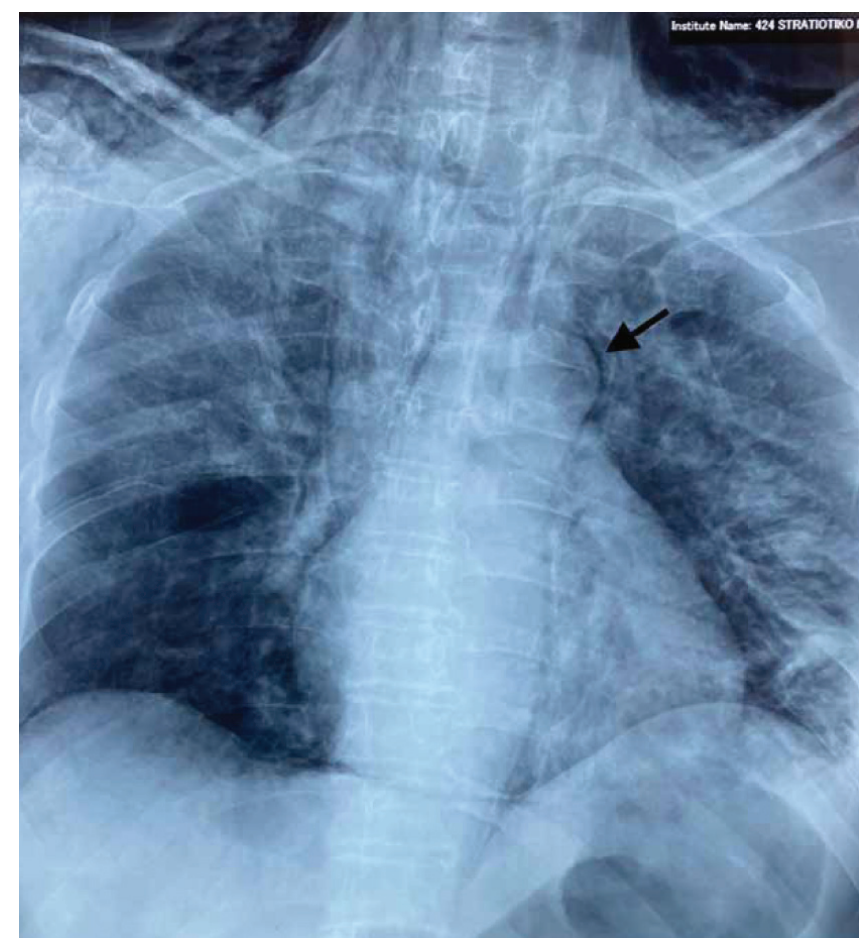

Figure 3. Chest CT on day 15 of illness. Presence of pneumo-mediastinum, subcutaneous emphysema of the thoracic wall and the neck as well as diffuse bilateral ground glass opacities. There is a trace of pneumothorax in the left lung (red arrow)

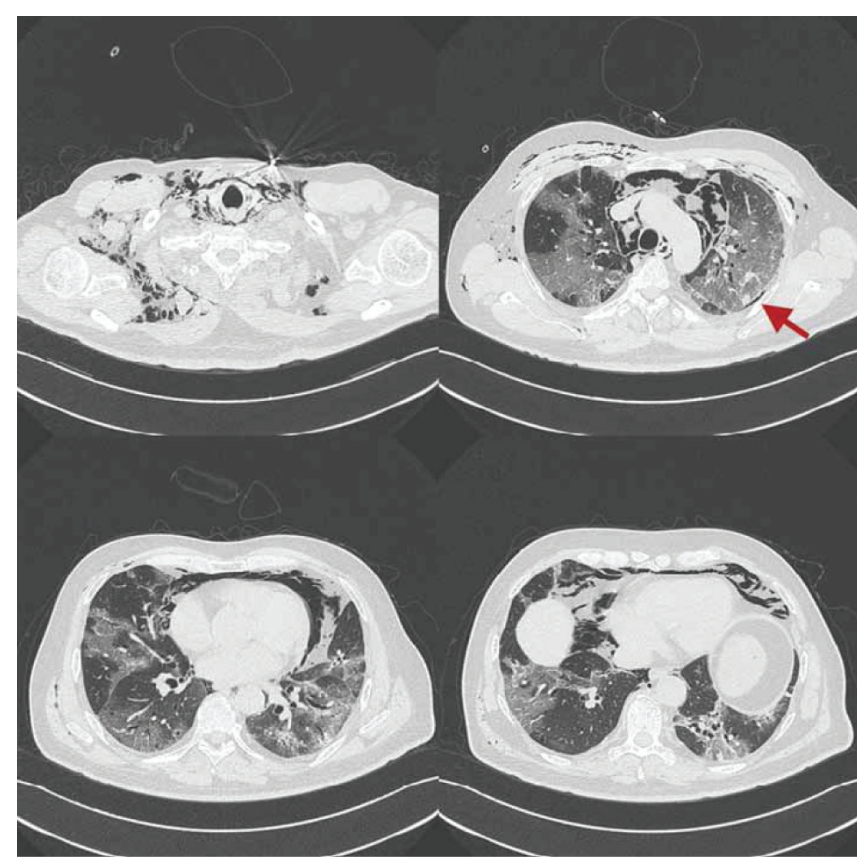

(p02/FiO2 ratio: 69) as well as in prone position for most hours of the day.

On day 15 of illness, while the patient continued to be severely ill (pO2/FiO2 ratio: 75; mostly in prone position on HFNC 60 lpm FiO2 90\%, dyspneic at minimal effort without signs of hemodynamic compromise) a new chest $X$-ray showed pneumomediastinum and subcutaneous emphysema of the neck and chest wall (Figure 2). A subsequent chest computed tomography (CT) demonstrated the extension of the pneumomediastinum and subcutaneous emphysema and revealed diffuse bilateral ground glass opacities (Figure 3). The patient reported no pain of the chest or neck and no new onset dyspnea.

The pneumomediastinum and the subcutaneous emphysema were managed conservatively, while pharmacological treatment and oxygen therapy for COVID-19 were continued. On day 18 of the disease, a new chest X-ray showed complete resolution of the pneumomediastinum and the subcutaneous emphysema (Figure 4). The patient remained clinically stable and respiratory support was gradually deescalated until discharge.

\section{DISCUSSION}

Pneumomediastinum (PM) is defined as the presence of air in the mediastinum and is characterized as either secondary or spontaneous ${ }^{1,2}$. The latter appears as the result of either trauma or iatrogenic procedures, such as intubation or central 
Figure 4. Chest X-ray on day 18 of illness.

Absence of signs of air in the mediastinum, no signs of subcutaneous emphysema and normal appearance of the lung parenchyma

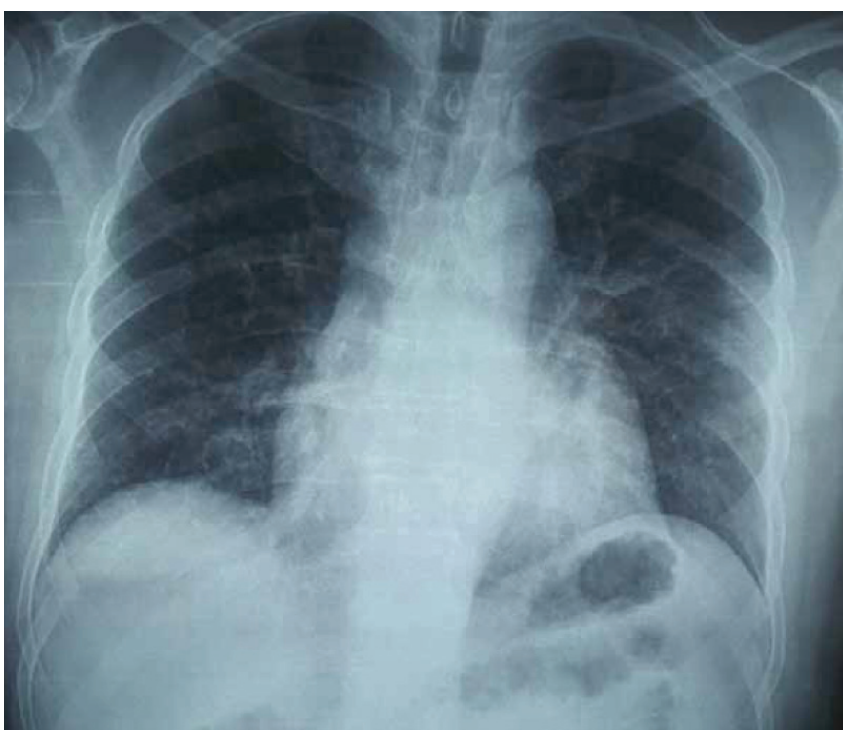

line placement ${ }^{1,2}$. Spontaneous pneumomediastinum (SPM) refers to the cases in which such traumatic history is absent, but there is an association with preexisting respiratory disease (such as asthma, interstitial lung disease and recent respiratory infection) and certain triggering events (such as persistent cough and strenuous physical activity) ${ }^{2}$. In the case presented here, SPM was diagnosed in view of absence of traumatic or iatrogenic causes, albeit the patient had no previous history of respiratory disease and did not suffer from persistent cough.

Although a few sporadic cases of SPM in the course of other viral respiratory illness ${ }^{3-6}$ were reported, there is growing evidence of SPM linked to COVID-19, already during this first year of the pandemic ${ }^{7-40}$. Despite their relatively small number, there is marked heterogeneity regarding the diagnostic approach, the need for noninvasive (NIV) or mechanical ventilation, the degree and means of oxygen therapy delivered, the co-presence or absence of pneumothorax and subcutaneous emphysema (SE), and clinical outcomes (Table 1 ).

In our case, the patient had no clinical or radiological signs of SE or PM on admission and we believe that he developed

Table 1. Total of cases appearing in PubMed search regarding SPM and COVID-19. There are a total of 101 cases of SPM related to COVID-19, originated in a variety of countries. Among the 101 patients with SPM, 24 patients had concomitant pneumothorax (23.7\%) and $64(63 \%)$ were found with concomitant SE. There were $25(24.7 \%)$ patients who had received lung protective invasive ventilation and only 2 patients on NIV, prior to SPM diagnosis. Rest of the patients (73\%) were delivered oxygen therapy via oxygen masks and 1 patient was on HFNC

\begin{tabular}{|c|c|c|c|c|c|c|}
\hline Author & Country & $\begin{array}{l}\text { Number } \\
\text { of } \\
\text { patients } \\
\text { with } \\
\text { SPM }\end{array}$ & $\begin{array}{l}\text { SARS-Cov-2 } \\
\text { infection } \\
\text { confirmation }\end{array}$ & $\begin{array}{c}\text { Mechanical } \\
\text { ventilation } \\
\text { prior } \\
\text { to SPM } \\
\text { diagnosis }\end{array}$ & $\begin{array}{l}\text { Concomitant } \\
\text { pneumothorax }\end{array}$ & $\begin{array}{l}\text { Concomitant } \\
\text { subcutaneous } \\
\text { emphysema }\end{array}$ \\
\hline Lemmers et al. ${ }^{7}$ & Italy & 23 & RT-PCR & $\begin{array}{c}23 / 23 \\
\text { (intubated in } \\
\text { ICU) }\end{array}$ & $0 / 23$ & $23 / 23$ \\
\hline Manna et al. ${ }^{8}$ & USA & 11 & RT-PCR & $0 / 11$ & $1 / 11$ & $11 / 11$ \\
\hline Diaz et al. ${ }^{9}$ & USA & 3 & RT-PCR & $0 / 3$ & $1 / 3$ & $0 / 3$ \\
\hline Mohan et al. ${ }^{10}$ & USA & 1 & RT-PCR & $0 / 1$ & $0 / 1$ & $1 / 1$ \\
\hline Gorospe et al. ${ }^{11}$ & Spain & 4 & RT-PCR & $0 / 4$ & $0 / 4$ & $2 / 4$ \\
\hline Urigo et al. ${ }^{12}$ & UK & 1 & RT-PCR & $0 / 1$ & $0 / 1$ & $1 / 1$ \\
\hline Quincho-Lopez et al. ${ }^{13}$ & Peru & 2 & (+) COVID-19 IgM, IgG & $0 / 2$ & $1 / 2$ & $0 / 2$ \\
\hline Zhou et al. ${ }^{14}$ & China & 1 & RT-PCR & $0 / 1$ & $0 / 1$ & $0 / 1$ \\
\hline Wang et al. ${ }^{15}$ & China & 1 & RT-PCR & $0 / 1$ & $1 / 1$ & $1 / 1$ \\
\hline Wang $\mathrm{J}$ et al. ${ }^{16}$ & China & 1 & RT-PCR & NIV 1/1 & $0 / 1$ & $0 / 1$ \\
\hline Loffi et al. ${ }^{17}$ & Italy & 6 & RT-PCR & $0 / 6$ & $0 / 6$ & $3 / 6$ \\
\hline Shan et al. ${ }^{18}$ & China & 1 & RT-PCR & $0 / 1$ & $1 / 1$ & $1 / 1$ \\
\hline Lopez Vega $^{19}$ & Spain & 3 & RT-PCR & $0 / 3$ & $2 / 3$ & $0 / 3$ \\
\hline Al-Azzawi et al. ${ }^{20}$ & USA & 3 & RT-PCR & $2 / 3$ & $0 / 3$ & $3 / 3$ \\
\hline
\end{tabular}


Table 1. Continued

\begin{tabular}{|c|c|c|c|c|c|c|}
\hline Author & Country & $\begin{array}{l}\text { Number } \\
\text { of } \\
\text { patients } \\
\text { with } \\
\text { SPM }\end{array}$ & $\begin{array}{l}\text { SARS-Cov-2 } \\
\text { infection } \\
\text { confirmation }\end{array}$ & $\begin{array}{c}\text { Mechanical } \\
\text { ventilation } \\
\text { prior } \\
\text { to SPM } \\
\text { diagnosis }\end{array}$ & $\begin{array}{l}\text { Concomitant } \\
\text { pneumothorax }\end{array}$ & $\begin{array}{l}\text { Concomitant } \\
\text { subcutaneous } \\
\text { emphysema }\end{array}$ \\
\hline Eperjesiova et al. ${ }^{21}$ & USA & 7 & $\mathrm{n} / \mathrm{a}$ & $0 / 7$ & $2 / 7$ & $4 / 7$ \\
\hline Marsico et al. ${ }^{22}$ & Spain & 1 & $\mathrm{n} / \mathrm{a}$ & $0 / 1$ & $0 / 1$ & $1 / 1$ \\
\hline Jansssen et al. ${ }^{23}$ & The Netherlands & 1 & RT-PCR & $0 / 1$ & $0 / 1$ & $0 / 1$ \\
\hline Elhakim et al. ${ }^{24}$ & USA & 1 & RT-PCR & $0 / 1$ & $1 / 1$ & $1 / 1$ \\
\hline Mimouni et al. ${ }^{25}$ & Morocco & 1 & RT-PCR & $0 / 1$ & $0 / 1$ & $0 / 1$ \\
\hline Kong at al. ${ }^{26}$ & China & 1 & RT-PCR & $0 / 1$ & $0 / 1$ & $0 / 1$ \\
\hline Hazariwala et al. ${ }^{27}$ & USA & 2 & RT-PCR & $0 / 2$ & $2 / 2$ & $2 / 2$ \\
\hline Gillepsie et al. ${ }^{28}$ & USA & 1 & RT-PCR & $0 / 1$ & $1 / 1$ & $1 / 1$ \\
\hline Colmenero et al. ${ }^{29}$ & Spain & 1 & $\mathrm{n} / \mathrm{a}$ & $0 / 1$ & $1 / 1$ & $0 / 1$ \\
\hline Kolani et al..$^{30}$ & Morocco & 1 & RT-PCR & $0 / 1$ & $0 / 1$ & $0 / 1$ \\
\hline Belini et al. ${ }^{31}$ & Italy & 1 & RT-PCR & $0 / 1$ & $0 / 1$ & $0 / 1$ \\
\hline Juárez-Lloclla et al. ${ }^{32}$ & Spain & 11 & $\mathrm{n} / \mathrm{a}$ & $0 / 11$ & $5 / 11$ & $5 / 11$ \\
\hline Brogna et al. ${ }^{33}$ & Italy & 2 & RT-PCR & $0 / 2$ & $1 / 2$ & $0 / 2$ \\
\hline Li et al. ${ }^{34}$ & USA & 1 & RT-PCR & $0 / 1$ & $0 / 1$ & $0 / 1$ \\
\hline Oye et al. ${ }^{35}$ & USA & 2 & RT-PCR & $0 / 2$ & $2 / 2$ & $0 / 2$ \\
\hline Pingui et al. ${ }^{36}$ & China & 1 & RT-PCR & $0 / 1$ & $0 / 1$ & $0 / 1$ \\
\hline Tucker et al. ${ }^{37}$ & USA & 2 & RT-PCR & $0 / 2$ & $1 / 2$ & $1 / 2$ \\
\hline Zayet et al. ${ }^{38}$ & France & 1 & RT-PCR & $0 / 1$ & $1 / 1$ & $1 / 1$ \\
\hline Vazzava et al. ${ }^{39}$ & Italy & 1 & RT-PCR & NIV $1 / 1$ & $0 / 1$ & $1 / 1$ \\
\hline Wegner et al. ${ }^{40}$ & UK & 1 & RT-PCR & $0 / 1$ & $0 / 1$ & $1 / 1$ \\
\hline
\end{tabular}

SPM between day 10 and day 14 of disease, while being hospitalized (Figure 1). This appears in line with similar cases reported in non-intubated patients where the mean time of SE/SPM appearance was 13.3 days ${ }^{12}$.

PM most commonly presents with chest pain; however, up to $50 \%$ of SPM cases are characterized by the absence of specific clinical symptoms ${ }^{1}$. Accompanying SE can be detected in up to two-thirds of patients with PM cases and is usually characterized by neck pain and swelling ${ }^{1}$. In our case, there were no symptoms or signs of clinical deterioration when SPM and SE occurred, with chest radiography revealing these complications and providing a more accurate understanding of the patient's clinical status. This highlights the importance of regular radiological monitoring for hospitalized patients with COVID-19. Although SPM is mainly characterized by a benign clinical course and is usually self-limited $^{1,2}$, as in the case presented here, COVID-19 pneumonia carries the risk of sudden deterioration and, in this setting, occurrence of SPM/SE could lead to further or even fatal cardiorespiratory compromise.

The pathophysiology of SPM lies in alveolar rupture and the ensuing spread of air along the interstitial bronchovascular structures towards the hila and subsequently to the mediastinum. From there, air may track towards the loose anatomic structures of the chest wall and the neck $2,9,12,41$. This mechanism was first suggested by Macklin in $1939^{1,2}$, based on experiments in a cat model. The so called 'Macklin effect' can nowadays be demonstrated in chest CT imaging as linear collections of air adjacent to the bronchovascular sheaths ${ }^{42}$. On the basis of the described pathophysiology, pneumothorax only sporadically coexists with SPM/SE6,12. Similarly, in the case presented here, there was only a trace of pneumothorax in the left lung (Figure 3).

Barotrauma induced by positive airway pressures, applied during invasive ventilation, does not appear to be a perquisite for the development of COVID-19 related SPM ${ }^{7}$. In our case, the patient was on HFNC $60 \mathrm{lpm}$, which has been estimated to produce a maximum positive end-expiratory pressure (PEEP) of $5 \mathrm{mmHg}$, only when the patient mouth is closed, and which immediately disappears by opening the mouth ${ }^{43}$. Therefore, the cause of SPM in our patient can be mainly attributed to the extent and severity of COVID-19, as demonstrated by diffuse bilateral ground glass opacities in chest CT (Figure 3) leading to alveolar damage and rupture, 
rather than to the unstable low degree of PEEP applied by the HFNC. Moreover, SPM does not occur more frequently in patients on NIV for any etiology, whereas there are some cases of COVID-19 related SPM in patients on NIV ${ }^{12}$.

\section{CONCLUSION}

Further research is warranted to better understand the role of SPM in the prognosis of COVID-19. In many of the cases reported, clinical outcome was poor, most likely due to the severity of COVID-19 and not because of the development of SPM/SE ${ }^{7,12}$. In our case, the outcome was not fatal, but the patient required longer hospital stay to achieve gradual de-escalation of the oxygen therapy compared to other patients with analogous disease severity. Based on its benign character, it has been proposed that SPM in the course of COVID-19 does not alter the initial prognosis per se but could be a marker of extended disease and poor prognosis ${ }^{12}$.

\section{CONFLICTS OF INTEREST}

The authors have completed and submitted the ICMJE Form for Disclosure of Potential Conflicts of Interest and none was reported.

\section{FUNDING}

There was no source of funding for this research.

\section{DATA AVAILABILITY}

The data supporting this research cannot be made available for privacy reasons.

\section{PROVENANCE AND PEER REVIEW}

Not commissioned; externally peer reviewed.

\section{REFERENCES}

1. Kouritas VK, Papagiannopoulos K, Lazaridis G, et al. Pneumomediastinum. J Thorac Dis. 2015;7(Suppl 1):S44-S49. doi:10.3978/j.issn.2072-1439.2015.01.11

2. Sahni S, Verma S, Grullon J, Esquire A, Patel P, Talwar A. Spontaneous pneumomediastinum: time for consensus. N Am J Med Sci. 2013;5(8):460-464. doi:10.4103/1947-2714.117296

3. Chekkoth SM, Supreeth RN, Valsala N, Kumar P, Raja RS. Spontaneous pneumomediastinum in H1N1 infection: uncommon complication of a common infection. J R Coll Physicians Edinb. 2019;49(4):298-300. doi:10.4997/JRCPE.2019.409

4. Zuo Y, Yang Y, Hong J, et al. Analysis of diagnosis and treatment of 15 cases of severe influenza A. Article in Chinese. Zhonghua Er Ke Za Zhi. 2014;52(2):142-145. doi:10.3760/cma.j.issn.0578-1310.2014.02.014

5. Katsidzira L, Fana GT, Makunike-Mutasa R, Ferrand RA. Pneumomediastinum in an HIV-infected patient with cytomegalovirus pneumonitis. Int J STD AIDS. 2011;22(3):179-180. doi:10.1258/ijsa.2010.010291

6. Chu CM, Leung YY, Hui JY, et al. Spontaneous pneumomediastinum in patients with severe acute respiratory syndrome. Eur Respir J. 2004;23(6):802-804. doi:10.1183/09031936.04.00096404

7. Lemmers DHL, Abu Hilal M, Bnà C, et al. Pneumomediastinum and subcutaneous emphysema in COVID-19: barotrauma or lung frailty? ERJ Open Res. 2020;6(4):00385-2020. doi:10.1183/23120541.00385-2020

8. Manna S, Maron SZ, Cedillo MA, et al. Spontaneous subcutaneous emphysema and pneumomediastinum in non-intubated patients with COVID-19. Clin Imaging. 2020;67:207-213. doi:10.1016/j.clinimag.2020.08.013

9. Diaz A, Patel D, Sayedy N, Anjum F. COVID-19 and Spontaneous Pneumomediastinum: A case series. Heart Lung. 2021;50(2):202-205. doi:10.1016/j.hrtlng.2020.12.002

10. Mohan V, Tauseen RA. Spontaneous pneumomediastinum in COVID-19. BMJ Case Rep. 2020;13(5):e236519. doi:10.1136/bcr-2020-236519

11. Gorospe L, Ayala-Carbonero A, Ureña-Vacas A, et al. Spontaneous Pneumomediastinum in Patients With COVID-19: A Case Series of Four Patients. Neumomediastino espontáneo en pacientes con COVID-19: una serie de cuatro casos. Arch Bronconeumol. 2020;56(11):754-756. doi:10.1016/j.arbres.2020.06.008

12. Urigo C, Soin S, Sahu A. Spontaneous pneumomediastinum as a complication of a COVID-19 related pneumonia: case report and review of literature. Radiol Case Rep. 2020;15(12):2577-2581. doi:10.1016/j.radcr.2020.09.052

13. Quincho-Lopez A, Quincho-Lopez DL, Hurtado-Medina FD. Case Report: Pneumothorax and Pneumomediastinum as Uncommon Complications of COVID-19 PneumoniaLiterature Review. Am J Trop Med Hyg. 2020;103(3):11701176. doi:10.4269/ajtmh.20-0815

14. Zhou C, Gao C, Xie Y, Xu M. COVID-19 with spontaneous pneumomediastinum. Lancet Infect Dis. 2020;20(4):510. doi:10.1016/S1473-3099(20)30156-0

15. Wang W, Gao R, Zheng Y, Jiang L. COVID-19 with spontaneous pneumothorax, pneumomediastinum and subcutaneous emphysema. J Travel Med. 2020;27(5):taaa062. doi:10.1093/jtm/taaa062

16. Wang J, Su X, Zhang T, Zheng C. Spontaneous Pneumomediastinum: A Probable Unusual Complication of Coronavirus Disease 2019 (COVID-19) Pneumonia. Korean J Radiol. 2020;21(5):627-628. doi:10.3348/kjr.2020.0281

17. Loffi M, Regazzoni V, Sergio P, et al. Spontaneous pneumomediastinum in COVID-19 pneumonia. Monaldi Arch Chest Dis. 2020;90(4):1399. doi:10.4081/monaldi.2020.1399

18. Shan S, Guangming L, Wei L, Xuedong Y. Spontaneous pneumomediastinum, pneumothorax and subcutaneous emphysema in COVID-19: case report and literature review. Rev Inst Med Trop Sao Paulo. 2020;62:e76. doi:10.1590/S1678-9946202062076

19. López Vega JM, Parra Gordo ML, Diez Tascón A, Ossaba Vélez S. Pneumomediastinum and spontaneous pneumothorax as an extrapulmonary complication of 
COVID-19 disease. Emerg Radiol. 2020;27(6):727-730. doi:10.1007/s10140-020-01806-0

20. Al-Azzawi M, Douedi S, Alshami A, Al-Saoudi G, Mikhail J. Spontaneous Subcutaneous Emphysema and Pneumomediastinum in COVID-19 Patients: An Indicator of Poor Prognosis? Am J Case Rep. 2020;21:e925557. doi:10.12659/AJCR.925557

21. Eperjesiova B, Hart E, Shokr M, Sinha P, Ferguson GT. Spontaneous Pneumomediastinum/Pneumothorax in Patients With COVID-19. Cureus. 2020;12(7):e8996. doi:10.7759/cureus.8996

22. Marsico S, Del Carpio Bellido LA, Zuccarino F. Spontaneous Pneumomediastinum and Macklin Effect in COVID-19 Patients. Arch Bronconeumol. 2021;57(Suppl 1):67. doi:10.1016/j.arbres.2020.07.030

23. Janssen J, Kamps MJA, Joosten TMB, Barten DG. Spontaneous pneumomediastinum in a male adult with COVID-19 pneumonia. Am J Emerg Med. 2021;40:228.e3228.e5. doi:10.1016/j.ajem.2020.07.066

24. Elhakim TS, Abdul HS, Pelaez Romero C, Rodriguez-Fuentes Y. Spontaneous pneumomediastinum, pneumothorax and subcutaneous emphysema in COVID-19 pneumonia: a rare case and literature review. BMJ Case Rep. 2020;13(12):e239489. doi:10.1136/bcr-2020-239489

25. Mimouni H, Diyas S, Ouachaou J, et al. Spontaneous Pneumomediastinum Associated with COVID-19 Pneumonia. Case Rep Med. 2020;2020:4969486. doi:10.1155/2020/4969486

26. Kong N, Gao C, Xu MS, Xie YL, Zhou CY. Spontaneous pneumomediastinum in an elderly COVID-19 patient: $A$ case report. World J Clin Cases. 2020;8(16):3573-3577. doi:10.12998/wjcc.v8.i16.3573

27. Hazariwala V, Hadid H, Kirsch D, Big C. Spontaneous pneumomediastinum, pneumopericardium, pneumothorax and subcutaneous emphysema in patients with COVID-19 pneumonia, a case report. J Cardiothorac Surg. 2020;15(1):301. doi:10.1186/s13019-020-01308-7

28. Gillespie M, Dincher N, Fazio P, Okorji O, Finkle J, Can A. Coronavirus disease 2019 (COVID-19) complicated by Spontaneous Pneumomediastinum and Pneumothorax. Respir Med Case Rep. 2020;31:101232. doi:10.1016/j.rmcr.2020.101232

29. Vela Colmenero RM, Pola Gallego de Guzmán MD, Molina de la Torre MC. Spontaneous pneumothorax and pneumomediastinum in bilateral pneumonia due to COVID-19. Neumomediastino y neumotórax espontáneo en neumonía bilateral por COVID-19. Med Intensiva. 2020;44(9):591-592. doi:10.1016/j.medin.2020.05.020

30. Kolani S, Houari N, Haloua M, et al. Spontaneous pneumomediastinum occurring in the SARS-COV-2 infection. IDCases. 2020;21:e00806. doi:10.1016/j.idcr.2020.e00806

31. Bellini D, Lichtner M, Vicini S, Rengo M, Ambrogi C, Carbone I. Spontaneous pneumomediastinum as the only CT finding in an asymptomatic adolescent positive for COVID-19. BJR Case Rep. 2020;6(3):20200051. doi:10.1259/bjrcr.20200051

32. Juárez-Lloclla JP, León-Jiménez F, Urquiaga-Calderón J, et al. Spontaneous Pneumopericardium and Pneumomediastinum in Twelve COVID-19 Patients. Arch Bronconeumol. 2021;57(Suppl 1):86-88. doi:10.1016/j.arbres.2020.09.013

33. Brogna B, Bignardi E, Salvatore P, et al. Unusual presentations of COVID-19 pneumonia on CT scans with spontaneous pneumomediastinum and loculated pneumothorax: A report of two cases and a review of the literature. Heart Lung. 2020;49(6):864-868. doi:10.1016/j.hrtlng.2020.06.005

34. Li S, Chau E, Ghasem W, Sohn J, Yaghmour B. Air Should Not be There: A Case of Pneumomediastinum and Pneumopericardium in COVID-19. Cureus. 2020;12(11):e11696. doi:10.7759/cureus.11696

35. Oye M, Ali A, Kandah F, Chowdhury N. Two cases of spontaneous pneumomediastinum with pneumothorax in patients with COVID-19 associated pneumonia. Respir Med Case Rep. 2020;31:101308. doi:10.1016/j.rmcr.2020.101308

36. Lei P, Mao J, Wang P. Spontaneous Pneumomediastinum in a Patient with Coronavirus Disease 2019 Pneumonia and the Possible Underlying Mechanism. Korean J Radiol. 2020;21(7):929-930. doi:10.3348/kjr.2020.0426

37. Tucker L, Patel S, Vatsis C, et al. Pneumothorax and pneumomediastinum secondary to COVID-19 disease unrelated to mechanical ventilation. Case Rep Crit Care. 2020;2020:6655428. doi:10.1155/2020/6655428

38. Zayet S, Klopfenstein T, Mezher C, Gendrin V, Conrozier T, Ben Abdallah Y. Coronavirus disease 2019 with spontaneous pneumothorax, pneumomediastinum and subcutaneous emphysema, France. New Microbes New Infect. 2020;38:100785. doi:10.1016/j.nmni.2020.100785

39. Vazzana N, Ognibene S, Dipaola F. Pneumomediastinum and subcutaneous emphysema after noninvasive ventilation in a COVID-19 patient. Adv Respir Med. 2020;88(5):466-467. doi:10.5603/ARM.a2020.0141

40. Wegner U, Jeffery G, Abrajan O, Sampablo I, Singh C. Spontaneous Pneumomediastinum Associated With SARSCoV-2: Infrequent Complication of the Novel Disease. Cureus. 2020;12(7):e9189. doi:10.7759/cureus.9189

41. Giannaki M, Antoniadis A. Potential mechanisms of mediastinum involvement in SARS-COV-2 infection. Pneumon. 2020;33(4):171-174. Accessed January 28, 2021. http://www.pneumon.org/assets/files/789/ file816_762.pdf

42. Murayama S, Gibo S. Spontaneous pneumomediastinum and Macklin effect: Overview and appearance on computed tomography. World J Radiol. 2014;6(11):850-854. doi:10.4329/wjr.v6.i11.850

43. Drake MG. High-Flow Nasal Cannula Oxygen in Adults: An Evidence-based Assessment. Ann Am Thorac Soc. 2018;15(2):145-155. doi:10.1513/AnnalsATS.201707-548FR 